\title{
A CONCISE METHOD FOR ANALYZING THE ICE-MELTING PERFORMANCE OF A HEATED DISC
}

\author{
By J. F. LEA* \\ (Science and Technology Division, North American Exploration and Production Group, Sun Oil \\ Company, 503 North Central Expressway, P.O. Box 936, Richardson, Texas 75080, U.S.A.
}

\begin{abstract}
Shreve (1962) evaluated the performance of solid-nose hotpoints of various geometries. A more concise method for analysis of the special case of a flat disc melting into ice is presented here. In contrast to the numerical solution presented by Shreve, this method results in a closed analytical solution, based on constant properties, which is corrected using a property ratio scheme. This technique allows the substitution of various fluid properties into the solutions as might be required when considering contaminated or saline ice or other liquids. Shreve's method would require some additional numerical work to evaluate various properties because the temperature dependence of the viscosity of water is integrated into the results.

Results obtained for the flat disc using this method are shown to compare favorably with Shreve's, indicating that this type of analysis may be applicable to other melt-unit geometries.
\end{abstract}

RÉsumé. Une methode rapide pour analyser le fonctionnement d'un disque chauffant pour la fusion de la glace. Dans l'article de Shreve (1962), le fonctionnement de "têtes chauffantes" de diverses géométries était estimé. On présente ici une méthode plus rapide pour l'analyse du cas d'un disque plat fondant la glace. Contrastant avec la solution numérique présentée par Shreve, cette méthode aboutit à une solution analytique de forme simple, basée sur des propriétés constantes, qui est corrigée en utilisant des variables réduites. Cette technique permet la substitution dans les équations des propriétés de différents fluides comme ce pourrait être nécessaire en considérant une glace polluée ou saline ou d'autres liquides. La méthode de Shreve demanderait des calculs numériques supplémentaires pour prendre en compte des propriétés variées parce que ses résultats intégrent la loi de variation de la viscosité de l'eau en fonction de la température.

On montre que les résultats obtenus par la méthode rapide pour un disque plat supportent avantageusement la comparaison avec ceux de Shreve, ce qui indique que ce type d'analyse, de même que celui de Shreve, est applicable à d'autres géométries de tête fondante.

Zusammenfassung. Ein schnelles Verfahren zur Analyse der Eisschmelzleistung einer aufgeheizten Scheibe. In dem Beitrag von Shreve ( 1962 ) wird aus der Betrachtung des fliessenden Wasserfilmes zwischen der warmen Oberfläche und dem Eis auf die Leistung von "solid-nose hotpoints" verschiedener Gestalt geschlossen. Für die Analyse des Falles einer flachen, in das Eis einschmelzenden Scheibe, wird hier ein kürzeres Verfahren entwickelt und vorgestellt. Im Gegensatz zur der von Shreve angewandten numerischen Lösung liefert dieses Verfahren eine geschlossene analytische Lösung; es beruhr auf der Annahme konstanter Eigenschaften, wird jedoch mit Hilfe eines Schemas der Eigenschaftsverhältnisse verbessert. Dieses Vorgehen ermöglicht auch die Substitution verschiedener Flüssigkeitseigenschaften in die Gleichungen, wie sie bei der Betrachtung von verunreinigtem oder salzhaltigem Eis oder anderen Flüssigkeiten notwendig werden könnte. In Shreves Methode würde die Berücksichtigung verschiedener Eigenschaften einigen rechnerischen Mehraufwand erfordern, weil die Temperaturabhängigkeit der Viskosität des Wassers ein Bestandteil der Ergebnisse ist.

Die mit dem kürzeren Verfahren für die flache Scheibe erhaltenen Ergebnisse schneiden im Vergleich zu denen von Shreve günstig ab; alle Anzeichen sprechen dafür, dass diese Art der Analysê, wie die von Shreve, auch auf anders geformte Schmelzkörper anwendbar ist.

\section{Method of ANALYSIS}

A heated disc is considered to be melting into ice at the velocity $V$. The temperature of the escaping water drops from the disc temperature to the fusion temperature of the ice across the uniform distance $\delta$.

In the following transformations, the radial velocity $u$, and the axial velocity $v$ are nondimensionalized with $V$. The axial distance $z$ is related to the distance between the disc and ice $\delta$, and the radial coordinate $r$ is related to the disc radius, $R$. The variable $p$ indicates the pressure distribution in the melt water.

A prime (') indicates a dimensional quantity. The subscripts $w$ and i refer to "water" and "ice".

$$
\begin{array}{ll}
u=u^{\prime} \mid V, & v=v^{\prime} / V, \\
z=z^{\prime} / \delta, & r=r^{\prime} / R, \\
p=p^{\prime} / \rho_{\mathbf{w}} V^{2} . &
\end{array}
$$

* Present address: Department of Engineering Science, University of Arkansas, Fayetteville, Arkansas 7270I, U.S.A. 
The assumptions used to reduce the equations of motion are: (I) inertial forces are much less than viscous forces; (2) $\delta \ll R$; (3) steady state; (4) no body forces; (5) constant properties. The resultant equation for the $r$ direction is:

$$
\frac{\partial p}{\partial r}=\frac{1}{(R e)} \frac{\partial^{2} u}{\partial z^{2}}
$$

where

$$
(R e)=\frac{\rho_{\mathrm{w}} V R}{\mu}\left(\frac{\delta}{R}\right)^{2},
$$

$\rho_{\mathrm{w}}$ is the water density and $\mu$ is the water viscosity at a "mixed mean" temperature defined in Equation (14).

To solve for the velocity and pressure distribution, the following boundary conditions must be satisfied:

$$
\left.\begin{array}{rlrl}
u & =0 & \text { at } z=0 \\
u & =0 & \text { at } z=\mathrm{I} \\
v & =0 & \text { at } z=0 \\
v & =\rho_{\mathrm{i}} / \rho_{\mathrm{w}} & \text { at } z=\mathrm{I} \\
p=p_{\mathrm{o}} & \text { at } r=\mathrm{I} \\
p / \partial r=0 & \text { at } r=\mathrm{O}
\end{array}\right\} .
$$

Solving Equation (2) with the boundary conditions and using mass balance of the fluid gives the following expressions for the pressure and radial-velocity distributions:

$$
\begin{aligned}
& p=p_{0}-\frac{3 \rho_{\mathrm{i}}}{\rho_{\mathrm{w}}} \frac{(R / \delta)}{(R e)}\left(r^{2}-\mathrm{I}\right), \\
& u=3 \frac{\rho_{\mathrm{i}}}{\rho_{\mathrm{w}}}\left(\frac{R}{\delta}\right) r\left(z-z^{2}\right) .
\end{aligned}
$$

The gap thickness $\delta$ can be found by integrating Equation (4) over the disc area:

$$
\delta=\left(\frac{3 \rho_{\mathrm{i}} \mu V R^{2}}{2 \rho_{\mathrm{w}}\left(P^{\prime}-p_{\mathrm{o}}{ }^{\prime}\right)}\right)^{\prime}
$$

where $P^{\prime}$ indicates the effective average pressure acting on the disc.

An integral energy equation for the fluid layer is then derived. Conduction in the $r$ direction is neglected. Equating the conduction and convection terms yields the energy equation

$$
\frac{\mathrm{I}}{r} \frac{\partial}{\partial r} \int_{0}^{1} r u T \mathrm{~d} z=\frac{\rho_{\mathrm{i}}}{\rho_{\mathrm{w}}} \frac{R}{\delta}+\frac{R / \delta}{(P e)}\left[\left.\frac{\partial T}{\partial z}\right|_{z=\mathrm{I}}-\left.\frac{\partial T}{\partial z}\right|_{z=0}\right]
$$

where $T=T^{\prime} / T_{\mathrm{m}}$ and $T_{\mathrm{m}}$ is the fusion temperature; the Peclet number is $(P e)=\frac{\rho_{\mathrm{w}} c V \delta}{k}$, $c$ is the heat capacity of the water, and $k$ is the conductivity of the water.

The boundary conditions for temperature are:

$$
\left.\begin{array}{rlrl}
T=1 & \text { at } z=\mathrm{I} \\
\frac{\partial T}{\partial z}=-\frac{(P e)}{T_{\mathrm{m}}} \frac{\lambda}{c} \frac{\rho_{\mathrm{i}}}{\rho_{\mathrm{w}}}=G & \text { at } z=\mathrm{I}
\end{array}\right\}
$$

where $\lambda$ is the heat of fusion.

The solution of Equations (7) and (8) is:

$$
T=\mathrm{I}-G+F+z(G-2 F)+F z^{2}
$$

where

and $a$ is a constant of integration.

$$
\left.\begin{array}{l}
F=\frac{a}{r^{L}}+\frac{10 G}{{ }^{L} L} \\
L=2-\frac{40 \rho_{\mathrm{w}}}{3(P e) \rho_{\mathrm{i}}}
\end{array}\right\}
$$


If efficiency, $\eta$, is defined as the quantity of heat that is conducted into the ice directly below the disc over the total heat leaving the disc, the following equation results:

$$
\eta=\frac{\left.\int_{0}^{1} \frac{\partial T}{\partial z}\right|_{z=1} r \mathrm{~d} r}{\left.\int_{0}^{1} \frac{\partial T}{\partial z}\right|_{z=0} r \mathrm{~d} r}
$$

Evaluation of $\eta$ as $(P e) \rightarrow o$ indicates $a=0$ which makes $T$ independent of $r$. This is in agreement with Shreve's work ( 1962$)$, in which the isothermal surface assumption leads to a constant $\delta$ for a heated disc.

\section{COMPARISON OF RESULTS}

The temperature of the disc in Shreve's study was shown to be a function of the following dimensionless "performance number" for a disc:

$$
\mathcal{N}=\left\{\frac{\mu_{0} c^{3}}{4^{k^{3} \lambda^{4} \rho_{\mathrm{w}} W}}\right\} \frac{Q}{R}
$$

where $Q$ is the total input of heat, $W$ is the weight on the "hotpoint" or disc and $\mu_{0}$ is the water viscosity at $0^{\circ} \mathrm{C}$.

In order to conveniently relate the performance number $\mathcal{N}$ to the Peclet number, a dimensionless number $(P e)^{\star}$ is defined as

$$
(P e)^{\star}=(P e) \frac{\rho_{\mathrm{i}}}{\rho_{\mathrm{w}}}\left(\frac{\mu_{0}}{\mu}\right)^{-0.14}
$$

where $\mu$ and $(P e)$ are evaluated at the "mixed mean" temperature $\bar{T}$, between the disc and the ice.

$$
\bar{T}=\frac{\int_{0}^{1} u T \mathrm{~d} z}{\int_{0}^{1} u \mathrm{~d} z}=\mathrm{I}+G\left(\frac{\mathrm{I}}{L}-\frac{\mathrm{I}}{2}\right) .
$$

The factor $\rho_{\mathrm{i}} / \rho_{\mathrm{w}}$ is included in $(P e)^{\star}$ because Equation (9) appears in terms of $(P e) \cdot \rho_{\mathrm{i}} / \rho_{\mathrm{w}}$. The term $\left(\mu_{0} / \mu\right)^{-0.14}$ is a form of the "property ratio" scheme described by Kays (1966) which is commonly used to correct constant-property analytic solutions for effects of variable viscosity. The exponent, -0.14 , which has been used successfully with pipe-flow solutions for laminar flow of moderate to high Prandtl number liquids (Kays, I966), was found, after trial and error, to correct this solution to near the values obtained by Shreve using fresh-water viscosity data.

Shreve's performance number $\mathcal{N}$, and $(P e)^{\star}$ can now be related as

$$
\mathcal{N}=\left(\left(\frac{\mu_{0}}{\mu}\right)^{0.58} \frac{\left((P e)^{\star} \pi\right)^{3}}{6 E^{4}}\right)^{!}
$$

where $E$ is efficiency as defined by Shreve: the "ratio of the cross-sectional area of the 'hotpoint' to the cross-sectional area of the hole made in the ice".

We have described efficiency as the ratio of the quantity of heat conducted into the ice directly below the disc to the total heat leaving the disc. Since the heat from the disc which does not get conducted to the ice directly below serves instead to enlarge the cross-sectional area of the hole created, it can be seen that the two definitions are mathematically equivalent. 


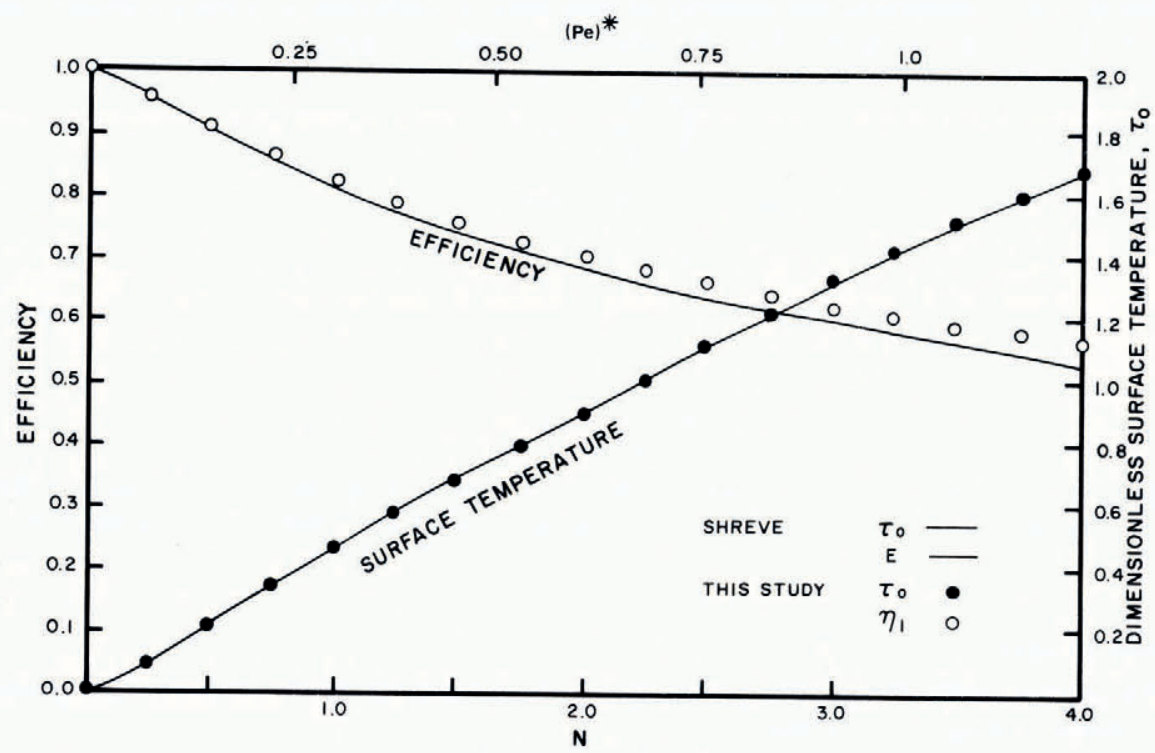

Fig. 1. E:ficiency and surface temperature related to performance number $\mathrm{N}$, and $(\mathrm{Pe})^{\star}$.

The results of this study and that of Shreve are compared in Figure $\mathrm{I}$. The term $\tau_{\mathrm{o}}$ defined by Shreve is disc temperature multiplied by $c / \lambda$ (heat capacity of water/heat of fusion). The discrepancy between the numerical solution using the more exact method of Shreve, and the constant-property method giving an analytical solution is seen to be very small. Also, the efficiencies $\eta$ and $E$ agree very well at low values of $\mathcal{N}$ and $(P e)^{\star}$, and differ by only a few percent at higher values of $\mathcal{N}$. The results indicate that this method is satisfactory for the analysis of a flat disc and should be considered for its possible application to other geometries.

MS. received 3 January 1974 and in revised form 23 July 1.974

\section{REFERENCES}

Kays, W. M., 1966. Convective heat and mass transfer. New York, McGraw-Hill Book Co., Inc.

Shreve, R. L. 1962. Theory of performance of isothermal solid-nose hotpoints boring in temperate ice. Journal of Glaciology, Vol. 4, No. 32, p. 151-60. 